\title{
Estimation of relative feed value, relative forage quality and net energy lactation values of some roughage samples by using near infrared reflectance spectroscopy
}

\section{Research Article}

Volume: 4, Issue: 3

December 2020

Pages: 109-118

\section{Article History}

Received: 07.09.2020

Accepted:27.10.2020

Available online:

28.10.2020

\begin{abstract}
Hasan ATALAY ${ }^{1}$, Fatih KAHRIMAN ${ }^{2}$
1. Department of Animal Nutrition and Nutritional Diseases, Faculty of Veterinary Medicine, Balikesir University, 10145, Balıkesir, Turkey, ORCID ID. 0000-0002-5744-7538. 2. Department of Field Crops, Faculty of Agriculture, Çanakkale Onsekiz Mart University, 17100, Çanakkale, Turkey, ORCID ID: 0000-0001-69440512
\end{abstract}

\begin{abstract}
The aim of this study is to determine the relative feed value (RFV), relative forage quality (RFQ) and net energy lactation (NEL) values of some roughage samples, based on the measurements taken from two different near infrared reflectance (NIR) devices. Corn silage $(n=18)$, alfalfa $(n=$ $9)$, oat grass hay $(n=15)$, wheat straw $(n=10)$ were used as roughage samples and NIR measurements were taken from these samples in two ways. In the study, two different NIR (NIR1, NIR2) devices were used and nutrient values of roughage samples which were used were determined. The reference chemical analyzes of the roughage samples used in the study were made in the laboratory as dry matter. After the determination of the nutritional values, by adding these nutritional values (Dry matter, ether extract, crude protein, ash, neutral detergent fiber, acid detergent fiber) to the RFV, RFQ, NEL equations, RFV, RFQ and NEL values of each roughage sample were calculated. Meanwhile, the roughage samples used in the study were also analyzed in NIR devices and after the nutritional values were determined, these nutritional values were written in the RFV, RFQ, NEL equations thus RFV, RFQ, NEL values of each roughage samples were calculated separately for each device. Relationships between predictions obtained from NIR1 and NIR2 devices and reference chemical analysis values were determined by statistical tests. It was determined that the type of device and sample used had an important effect on the relationships between the results obtained from the reference analyzes and the predictions based on NIR measurements. Regression coefficients between RVF, RFQ and NEL values obtained from NIR1 and NIR2 devices and RVF, RFQ and NEL values obtained from reference (REF) analysis were determined to be 0.37 and 0.50 . Among the roughage types, the highest similarity between NIR results and reference analysis results was found in alfalfa samples. The study results showed that indirect estimation by NIR relating to RVF, RFQ and NEL parameters is possible depending on the sample type and that there is a need for calibration improvement studies to determine these parameters directly with NIR.
\end{abstract}

Keywords: roughages, relative feed value, relative forage quality, net energy lactation, NIR spectroscopy

DOI: https://doi.org/10.30704/http-www-jivs-net.791669

To cite this article: Atalay, H., Kahriman, F. (2020). Estimation of relative feed value, relative forage quality and net energy lactation values of some roughage samples by using near infrared reflectance spectroscopy. Journal of Istanbul Veterinary Sciences, 4(3), 109-118. Abbreviated Title: J Ist Vet Sci

\section{Introduction}

Roughages are the most abundant and inexpensive source of feed that are extensively used in ruminant feeding. The quality of the roughages is primarily indicated by the amount and composition of their structural carbohydrate contents. Specifically, the NDF and ADF fractions that form the cell wall of plants are

\footnotetext{
*Corresponding Author: Hasan Atalay
}

E-mail: hasanatalay@balikesir.edu.tr important parameters determining their intake and digestibility. Various indexes are used to express the quality of roughages depending on their NDF and ADF content. These indexes are relative feed value (RFV) and relative forage quality (RFQ). Relative feed value (RFV) is an estimated index used in the quality

Journal home page: www.jivs.net http://dergipark.gov.tr/http-www-jivs-net 
assessment of alfalfa grass and other roughages. Relative forage quality (RFQ) is another feed evaluation system that considers NDF digestibility. The RFQ is a more developed index than the RFV index, as it better reflects the expected performance of cattle consuming roughage. The digestibility of NDF determines rumen fullness and digesta flow rate ultimately affecting the dry matter consumption. Total digestible nutrients (TDN) are used to determine the RFQ (Hayırlı 2016; Sheaffer et al., 1995; Ball et al., 2007).

Various analyzes such as weende analysis, Van soest analysis, in vitro ruminal and enzymatic techniques are used to determine the nutrient matter content of roughages. However, since chemicals are used in all these techniques, time and cost calculations are required to be made. Studies continue to explore more economically efficient and less time consuming alternative methods in analyzing the chemical composition of the feeds and forages. Near infrared reflectance spectroscopy (NIRS) is one of the important alternatives studied on this subject. The NIRS method is an analysis method that calculates the nutrient content of feeds based on mathematical modeling without using chemicals (Goldman et al., 1987; Parrini et al,. 2019; Ünal, 2005; Kellems and Church, 2010).

Near Infrared Analysis is a method developed and used by the feed industry to evaluate the nutrient content of feeds and determine their quality levels (Marten et al., 1989). Yang et al. reported that NIR spectroscopy can be used successfully to determine the content of crude protein (CP), ADF, NDF and water soluble carbohydrate (WSC) in Italian ryegrass (Lolium multiflorum) (Yang et al., 2017). In another study (Rushing et al., 2016) on the use of NIR in feed quality measurements in wild rye (Elymus glabriflorus), calibration models were created for different feed quality evaluations such as relative feed value as well as general quality evaluations such as ADF and NDF. Research findings showed that feed quality evaluations for the feed type used can be successfully performed with NIR (Rushing et al., 2016). Most of the studies conducted have focused on general quality evaluations such as ADF, NDF and CP content. to best of our knowledge, there is no study on the calculation of the indexes used in the measurement of feed quality such as RFV and RFQ with the values determined by NIR and their association with the indexes calculated over the values obtained with reference analysis. No study has addressed the effect of the measured feed sample type [as fed (in natural condition) or as dry basis (dry matter)] on NIR estimation results. It is thought that studies on this subject will provide important findings on how feed quality evaluations can be made with NIR in a more practical way.

Therefore, the purpose of this study is to investigate whether it is possible to determine the Relative Feed Value (RFV), RFQ and lactation energy (NEL) of some roughages by using the NIR analysis results and to determine the effect of the sample form (as fed basis or dry matter basis) used in the analyzes and the effect of feed group from which the sample was taken.

\section{Materials and Methods}

The feed samples (corn silage, alfalfa, oat grass hay, wheat straw) used in the research were produced in Balıkesir. Roughage samples were taken fresh and weighed $0.5 \mathrm{~kg}$ from farms and brought to the laboratory in airtight bags and kept at $-20^{\circ} \mathrm{C}$ until analysis. Wet feed samples (silage) with known weights were dried in the oven for 48 hours at $60^{\circ} \mathrm{C}$ until their weight did not change and the dry matter level was determined. Air-dried and weight known feed samples were dried in the oven at $105^{\circ} \mathrm{C}$ for 4 hours and the dry matter level was determined (AOAC, 1997). Dried feed samples were ground in the mill (Retsch ZM 200 ultra centrifugal mill, $1 \mathrm{~mm}$ sieve) for analysis.

Reference analysis (Chemical analysis): Reference (chemical) analysis of roughage samples used in the study were made in Balıkesir University Veterinary Faculty Animal Nutrition and Nutrition Diseases Laboratory, according to specified method for dry matter (DM, method 934.01), ash (method 942.05), crude protein (CP, method 990.03), ether extract (EE, method 920.39) (AOAC, 1997) and reference analysis values (nutrient values) were determined. (NDF) and (ADF) analysis of feed samples were made by using Gerhard FT12 Fiber Analyzer (Gerhardt, 2010) automatic device according to the methods reported by Van Soest et al. (1991). By using the nutrient values (NDF, ADF, DM, CP, EE, ash) obtained as a result of the analysis of feed samples, RFV, RFQ, and NEL levels were calculated according to the equations reported in NRC (2001) (Samiei et al., 2015).

NIR spectroscopy measurements: NIR measurements were performed on two different NIR devices. One of these devices is a desktop NIR device (Spectrastar 2400D, Unity Scientific, USA) and the other is a portable NIR device (Dinamica Generale Agri NIR Analyzer, Italy).

To make spectral measurements from roughage samples and to determine the feed quality characteristics in the desktop NIR device, spectral data of the feed samples (corn silage, alfalfa, oat grass hay, 
wheat straw) were collected separately in both natural state (as fed basis) and dry matter basis, between 1200-2400 $\mathrm{nm}$ sized and at a frequency of 1 $\mathrm{nm}$. Dry matter (DM), ash, crude protein (CP), ether extract (EE), Neutral Detergent Fiber (NDF) and Acid Detergent Fiber (ADF) values of the samples were determined by applying the INGOT calibration model (Maize Silage and Forage, Unitiy Scientific, USA) to the collected spectral data.

For the measurements to be made in the portable NIR device, the feed samples were placed in the measurement compartment of the device and spectral measurement was made. After measurement, $D M$, ash, CP, EE, NDF and ADF values were determined by using the calibration defined on the device.

In the study, two different NIR devices, desktop and portable, were used and nutrient values of roughage samples were determined. By placing the nutrient values taken from NIR spectroscopy in RFV, RFQ, NEL equations, the RVF, RFQ and NEL values of each roughage sample were calculated. RFV, RFQ and NEL values of roughage samples were calculated separately on both NIR devices as fed basis and dry matter basis.

Determination of relative feed value, relative forage quality and net energy lactation values: Using nutrient values determined according to reference (chemical) analyzes, RFV, RFQ, and NEL levels were calculated according to the equations specified in NRC (2001).

$\mathrm{NEL}=[0.866-(0.0077 * \mathrm{ADF})] * 2.2, \mathrm{NFC}=100-(\% \mathrm{CP}$ $+\% \mathrm{EE}+\%$ Ash + \% NDF)

Relative feed value (RFV) is an index used in the quality assessment of roughages. The RFV value was calculated according to the following equation.

$\mathrm{RFV}=\mathrm{DDM} * \mathrm{DMI} / 1.29=\mathrm{DDM} * \mathrm{DMI} * 0.775$

Where: DDM (Digestible dry matter) $=88.9-(0.779 *$ $\%$ ADF)

DMI (Dry matter intake $)=120 / \%$ NDF, ADF $=$ Acid detergent fiber (\% of DM)

Since relative forage quality (RFQ) index is more developed than RFV index, it reflects the expected performances of cattle consuming roughage more effectively. The RFQ value was calculated according to the following equation.

$\mathrm{RFQ}=(\mathrm{DMI} * \mathrm{TDN}) / 1.23$

Where: $\mathrm{DMI}=$ Dry matter intake $(\%$ of $\mathrm{BW}), \mathrm{BW}=$ Body weight, $\mathrm{DM}=$ Dry matter

TDN = Total digestible nutrients (\% of DM)

For legumes (alfalfa, clovers, and legumes/grass mixtures):
$\mathrm{DMI}=(120 / \mathrm{NDF})+(\mathrm{NDFD}-45) *(0.374 / 1350) * 100$

$\mathrm{TDN}=(\mathrm{NFC} * 0.98)+(\mathrm{CP} * 0.93)+(\mathrm{FA} * 0.97 * 2.25)+$ $(\mathrm{NDFn} *(\mathrm{NDFD} / 100))-7$

Where: NDF= Neutral detergent fiber (\% of DM), NDFD $=48$-hour in vitro NDF digestibility (\% of NDF), NDFD $=45$ is an average value for fiber digestibility of alfalfa and alfalfa/grass mixtures.

NFC $=$ Non fibrous carbohydrate $(\%$ of DM) $=100-$ (NDFn + CP + EE + ash),

$\mathrm{CP}=$ Crude Protein $(\%$ of DM), FA= Fatty acid (\% of $D M)=$ Ether extract -1 ,

NDFn $=$ Nitrogen free NDF = else estimated as NDFn= NDF * 0.93 (Samiei et al., 2015; Romero et al., 2014; Jaranyama and Garcia, 2004; Van Dyke and Anderson, 2000).

Statistical Analysis: The data obtained from the study were analyzed in SAS statistical package program (SAS Institute, 1999). Descriptive statistics on forage quality parameters were obtained by proc MEANS procedure. Variance analysis was used to determine the effect of the sample type of roughage, the device used in the study and the plant where the roughage is produced on the analysis results. Differences between the results obtained from different NIR devices of "Dry matter" and "as fed" feed samples and the reference data were compared with the LSD test. Correlation and regression analyzes were used to examine the relationships between data on feed quality values according to NIR devices in sample groups. Pearson moment correlation was used in correlation analysis and analyzes were performed with proc CORR command in SAS program. The relationships between simple linear regression graphics created in the Excel program and the reference analyzes and the feed quality values calculated from the data obtained from NIR devices were examined. By adding correlation test results to these graphs, the relationships between NIR estimates and reference analyzes were tried to be explained.

\section{Results}

In the NIR device, roughages were scanned both in natural (as fed basis) and dried (dry matter basis), and the graphic regarding the spectral data obtained from the desktop device (NIR1) belonging to the scanned area is given in Figure 1. As can be seen in this graph, dried corn silage samples had a much higher spectral reflection than other sample groups. Generally, spectral trends of other sample groups were similar. Since spectrum data could not be exported from the portable device (NIR2), the graphic for this device could not be presented. 


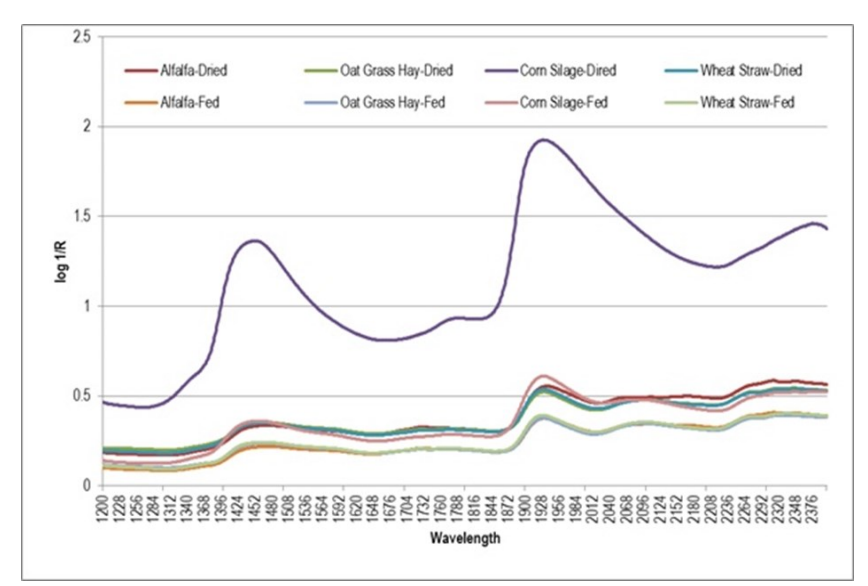

Figure 1. Spectra between $1200-2400 \mathrm{~nm}$ of roughage samples in natural state (as fed basis) and dried (dry matter basis).

The RFV, RFQ, and NEL values of the roughage samples used in the study were calculated separately by NIR analysis as "fed basis" and "dry matter basis". Descriptive statistics of NIR1, NIR2 and reference (REF) analysis results are presented in Table 1 . In both sample groups, the mean, standard deviation and ranges calculated with NIR devices were higher than the reference analyzes (Table1). It has been observed that the averages calculated by NIR and Reference analyzes in the feed samples prepared as "fed basis" have a closer average than the feed samples prepared as "dry matter".

Analysis of variance of RFV, RFQ and NEL values calculated according to NIR1, NIR2 and reference
(REF) analysis of roughage samples is shown in Table 2. When the table is examined, it is seen that the roughage samples used have an important effect on the calculation of RFV, RFQ and NEL values. In addition, sample type, roughage type and device interaction were also found important (Table 2).

It was observed that there was variation between the results obtained with different devices regarding RFV, RFQ and NEL values and the averages of the reference analysis results according to the calculated parameter. In general, the results of NIR1 and NIR 2 analyzes of roughages in both "as fed" and "dry matter" were found higher than the results obtained in the reference analysis. It was determined that there was no statistically significant difference among NIR1, NIR2 and reference analysis results in the alfalfa sample calculated "as fed" (Table 3). Similarly, it was determined that the difference between the NIR1 and NIR2 analysis results (NIR1 $=110.44$, NIR2 $=101.37$ ) and the reference analysis results ( $R E F=102.1)$ of the RFQ value in the alfalfa sample as dry matter was not significant. Significant differences were found in other sample groups between the reference analysis and averages determined by NIR estimates.

Regression analysis results showing the relationships between the reference analysis results regarding RFV, RFQ and NEL values and the predictions based on NIR measurements are presented in Figure 2 and the correlation analysis results are presented in Table 4. According to the

Table 1. Descriptive statistics of RFV, RFQ and NEL values calculated according to NIR1, NIR2 and reference (REF) analysis results of roughage samples in "as fed basis" and "dry matter basis" state.

\begin{tabular}{|c|c|c|c|c|c|c|c|c|c|}
\hline \multirow[b]{3}{*}{ Statistic } & \multicolumn{9}{|c|}{ Samples as fed basis } \\
\hline & \multicolumn{3}{|c|}{ RFV } & \multicolumn{3}{|c|}{ RFQ } & \multicolumn{3}{|c|}{ NEL } \\
\hline & NIR1 & NIR2 & REF & NIR1 & NIR2 & REF & NIR1 & NIR2 & REF \\
\hline $\mathrm{N}$ & 52 & 52 & 52 & 52 & 52 & 52 & 52 & 52 & 52 \\
\hline Mean & 114.8 & 103.4 & 90.8 & 109.3 & 102.2 & 85.7 & 1.3 & 1.2 & 1.2 \\
\hline St Dev. & 43 & 35.4 & 28.9 & 45.7 & 38.3 & 27 & 0.2 & 0.1 & 0.2 \\
\hline Min & 52.9 & 41.5 & 47.9 & 43.6 & 37.6 & 48.3 & 0.9 & 0.8 & 0.9 \\
\hline \multirow[t]{3}{*}{ Max } & 245.5 & 213.2 & 158 & 252.3 & 243 & 160.9 & 1.8 & 1.5 & 1.6 \\
\hline & \multicolumn{9}{|c|}{ Samples dry matter basis } \\
\hline & \multicolumn{3}{|c|}{ RFV } & \multicolumn{3}{|c|}{ RFQ } & \multicolumn{3}{|c|}{ NEL } \\
\hline Statistic & NIR1 & NIR2 & REF & NIR1 & NIR2 & REF & NIR1 & NIR2 & REF \\
\hline $\mathrm{N}$ & 52 & 52 & 52 & 52 & 52 & 52 & 52 & 52 & 52 \\
\hline Mean & 232.8 & 103.7 & 90.8 & 227 & 100.6 & 85.7 & 1.59 & 1.26 & 1.22 \\
\hline St. Dev. & 192.6 & 30.1 & 28.9 & 216.3 & 33.2 & 27.0 & 0.23 & 0.13 & 0.19 \\
\hline Min & 78.4 & 41.5 & 47.9 & 60.4 & 39.7 & 48.3 & 1.24 & 0.85 & 0.90 \\
\hline Max & 842.7 & 176.6 & 158 & 936.5 & 196.9 & 160.9 & 1.96 & 1.46 & 1.55 \\
\hline
\end{tabular}


Table 2. Variance analysis results for RFV, RFQ and NEL values of roughage samples.

\begin{tabular}{lcccc}
\hline & DF & $\begin{array}{c}\text { Relative forage } \\
\text { value }(\mathrm{RFV})\end{array}$ & $\begin{array}{c}\text { Relative forage } \\
\text { quality (RFQ) }\end{array}$ & $\begin{array}{c}\text { Net energy lacta- } \\
\text { tion }\left(\mathrm{NE}_{\mathrm{L}}\right)\end{array}$ \\
\cline { 2 - 5 } Sample Type & 1 & $121292.43^{* *}$ & $117049.8^{* *}$ & $0.59^{* *}$ \\
Species & 3 & $185275.75^{* *}$ & $216380.5^{* *}$ & $1.57^{* *}$ \\
Instrument & 2 & $207862.73^{* *}$ & $199188.7^{* *}$ & $1.82^{* *}$ \\
Sample $\times$ Species & 3 & $54824.51^{* *}$ & $69000.3^{* *}$ & 0.03 \\
Sample $\times$ Instrument & 2 & $120245.56^{* *}$ & $121783.5^{* *}$ & $0.48^{* *}$ \\
Species $\times$ Instrument & 6 & $88292.47^{* *}$ & $111879.7^{* *}$ & $0.15^{* *}$ \\
Sample $\times$ Species $\times$ Instrument & 6 & $55326.75^{* *}$ & $67639.5^{* *}$ & $0.04^{* *}$ \\
Error & 288 & 2077.75 & 2656.1 & 0.01 \\
\hline
\end{tabular}

** $\mathrm{p}<0.01$ Levels are taken as statistically significant

results of the regression analysis, it was understood that the sample group and the plant species from which the sample was obtained had a significant effect on the results for all quality parameters. It is also clear that the NIR device used has an impact on the results. As a result, for all feed quality parameters, the regression coefficients determined between the data obtained from the NIR1 device and the reference analysis were found to be significantly higher than that of the NIR2 device. The regression coefficient between the reference analyzes of the RFV value in the NIR1 device and the NIR estimates has shown similarity to the samples prepared "as fed" and "dry matter" (Figure 2a, Figure 2b). The highest difference between the regression coefficients for these sample groups was determined in the RFQ parameter such that the R2 value which was determined as 0.312 for the NIR1 device in the "dry matter" sample group was determined as 0.5063 in the "as fed" sample group. For NEL value, R2 value was found around $40 \%$ in both "dry matter" and "as fed" sample groups. The results obtained from the portable NIR device for the NEL parameter also show that the prediction success is higher than the other parameters. Based on these findings, it is possible to say that prediction success with NIR by using RFQ parameter is higher than other

Table 3. Multiple comparison test results of RFV, RFQ and NEL values calculated according to NIR1, NIR2 and reference (REF) analysis results of roughage samples in "as fed basis" and "dry matter basis" state.

\begin{tabular}{|c|c|c|c|c|c|c|}
\hline & \multicolumn{3}{|c|}{ Samples as fed basis } & \multicolumn{3}{|c|}{ Samples dry matter basis } \\
\hline & NIR1 & NIR2 & REF & NIR1 & NIR2 & REF \\
\hline RFV-Alfalfa & $113.76^{\mathrm{a}}$ & $125.36^{\mathrm{a}}$ & $110.06^{\mathrm{a}}$ & $137.41^{a}$ & $113.54^{b}$ & $110.06^{b}$ \\
\hline RFV-Oat & $90.05^{a}$ & $88.14^{a}$ & $74.63^{b}$ & $101.71^{a}$ & $95.35^{a}$ & $74.63^{b}$ \\
\hline RFV-Silage & $154.80^{\mathrm{a}}$ & $111.93^{b}$ & $114.00^{b}$ & $462.38^{a}$ & $111.93^{b}$ & $114.00^{b}$ \\
\hline RFV-Wheat & $81.06^{\mathrm{ab}}$ & $91.19^{a}$ & $55.89^{b}$ & $102.02^{a}$ & $92.78^{b}$ & $55.89^{b}$ \\
\hline RFV-All & $114.84^{\mathrm{a}}$ & $103.40^{a b}$ & $90.79^{b}$ & $232.80^{a}$ & $103.74^{b}$ & $90.79^{b}$ \\
\hline RFQ-Alfalfa & $101.34^{\mathrm{a}}$ & $117.64^{\mathrm{a}}$ & $102.08^{a}$ & $110.44^{\mathrm{a}}$ & $101.37^{\mathrm{a}}$ & $102.08^{a}$ \\
\hline RFQ- Oat & $81.18^{a b}$ & $87.07^{a}$ & $68.30^{\mathrm{b}}$ & $83.51^{a}$ & $92.65^{a}$ & $68.30^{\mathrm{b}}$ \\
\hline RFQ-Silage & $154.70^{\mathrm{a}}$ & $111.53^{b}$ & $108.56^{b}$ & $483.19^{a}$ & $111.53^{b}$ & $108.56^{b}$ \\
\hline RFQ-Wheat & $76.69^{\mathrm{ab}}$ & $94.13^{\mathrm{a}}$ & $55.96^{b}$ & $86.07^{\mathrm{ab}}$ & $92.37^{a}$ & $55.96^{b}$ \\
\hline RFQ-All & $109.25^{a}$ & $102.19^{a}$ & $85.71^{b}$ & $227.01^{a}$ & $100.64^{b}$ & $85.71^{b}$ \\
\hline$N E_{L}$-Alfalfa & $1.36^{\mathrm{a}}$ & $1.31^{\mathrm{a}}$ & $1.30^{\mathrm{a}}$ & $1.55^{\mathrm{a}}$ & $1.26^{\mathrm{b}}$ & $1.30^{\mathrm{b}}$ \\
\hline $\mathrm{NE}_{\mathrm{L}}-$ Oat & $1.27^{\mathrm{a}}$ & $1.20^{\mathrm{ab}}$ & $1.17^{b}$ & $1.40^{\mathrm{a}}$ & $1.26^{\mathrm{b}}$ & $1.17^{c}$ \\
\hline $\mathrm{NE}_{\mathrm{L}}$-Silage & $1.49^{a}$ & $1.31^{b}$ & $1.37^{b}$ & $1.88^{a}$ & $1.31^{b}$ & $1.37^{b}$ \\
\hline$N_{E_{L}}-$ Wheat & $1.17^{\mathrm{a}}$ & $1.13^{b}$ & $0.97^{b}$ & $1.37^{\mathrm{a}}$ & $1.16^{\mathrm{b}}$ & $0.97^{c}$ \\
\hline$N E_{L}-A l l$ & $1.34^{\mathrm{a}}$ & $1.24^{b}$ & $1.22^{b}$ & $1.59^{a}$ & $1.26^{b}$ & $1.22^{b}$ \\
\hline
\end{tabular}

Note: The differences between the averages shown with different letters on the rows of each sample group are statistically significant at $p<0.05$ level. 
parameters. In addition, according to the results obtained from the sample groups, it can be stated that it is possible to determine the RFV and NEL values of the ungrounded and sundried raw materials used in animal feeding by NIR. On these results, it should be known to which forage plant the feed sample belongs. As a matter of fact, as can be understood from the results of the correlation analysis, the results obtained according to the feed plant type confirm this situation (Table 4). According to the results of correlation analysis, the coefficients calculated over all samples between RFV and NEL parameters showed similarity in the feed samples prepared as "as fed" and "dry matter" on the NIR1 device and it was found that there was a moderate linear relationship in the positive direction. A similar situation was observed with the NIR2 device, but the correlations between reference analyzes and results obtained from the device were found relatively low (Table 4). Correlations between reference and NIR estimates of forage plant species used for each trait varied significantly.

It was noteworthy that the correlations between the reference values and NIR estimates were insignificant in the "as fed" and "dry matter" sample groups in the clover samples, which gave close averages between the groups according to the multiple comparison test results made on the averages. This indicates that the RFV, RFQ and NEL values obtained from clover samples are significantly different in the ranking between the reference and NIR estimates. On the other hand, although significant differences were observed between the RFV, RFQ and NEL values calculated based on reference and NIR estimates in LSD test results of wheat straw samples, medium-high correlations were calculated for RFV and RFQ parameters in correlation analysis. This situation arises from the high bias value determined in the regression equations for the mentioned parameters. In other words, it can be stated that if this bias value is subtracted from the NIR estimates, the prediction success for wheat straw may increase.

\section{Discussion}

The findings obtained from our study were similar to the findings of other studies performed with NIR. In the study conducted by Pehlevan and Özdoğan (2015), it was determined that there is a statistically significant difference between the crude protein, ether extract and NDF values obtained in cotton leaves according to NIR and chemical analysis methods. It was observed that there is a statistically significant difference between the crude protein, ether extract, ash, NDF, ADF values obtained according to NIR and chemical analysis methods in carob (Pehlevan and Özdoğan, 2015). With the NIR method, it was emphasized that maize fractions in different physiological maturity gave acceptable estimates of low and medium crude protein and net energy level with acceptable accuracy, but did not

Table 4. Correlation test between the results of NIR1, REF analysis and NIR2, REF analysis of RFV, RFQ and NEL values in "as fed basis" and "dry matter basis" state of roughage samples.

\begin{tabular}{|c|c|c|c|c|}
\hline & \multicolumn{2}{|c|}{ Samples as fed basis } & \multicolumn{2}{|c|}{ Samples dry matter basis } \\
\hline & NIR1-REF & NIR2-REF & NIR1-REF & NIR2-REF \\
\hline RFV-Alfalfa & 0.357 & -0.181 & 0.541 & 0.527 \\
\hline RFV-Oat & $0.625^{* *}$ & 0.246 & 0.219 & $0.643^{* *}$ \\
\hline RFV-Silage & -0.092 & -0.149 & 0.392 & -0.149 \\
\hline RFV-Wheat & $0.864 * *$ & 0.187 & $0.650^{*}$ & 0.469 \\
\hline RFV-All & $0.588^{* *}$ & $0.275^{*}$ & $0.627^{* *}$ & $0.321^{*}$ \\
\hline RFQ-Alfalfa & 0.448 & -0.337 & -0.501 & $0.833^{* *}$ \\
\hline RFQ- Oat & $0.877^{* *}$ & $0.557^{*}$ & $0.523^{*}$ & $0.561^{*}$ \\
\hline RFQ-Silage & -0.132 & -0.432 & $0.651 * *$ & -0.432 \\
\hline RFQ-Wheat & $0.789 * *$ & 0.256 & $0.623^{*}$ & 0.366 \\
\hline RFQ-All & $0.581^{* *}$ & 0.175 & $0.711^{* *}$ & 0.206 \\
\hline$N E_{L}$-Alfalfa & 0.226 & 0.188 & -0.108 & -0.035 \\
\hline $\mathrm{NE}_{\mathrm{L}}-\mathrm{Oat}$ & 0.294 & 0.049 & 0.044 & $0.721 * *$ \\
\hline $\mathrm{NE}_{\mathrm{L}}$-Silage & -0.028 & 0.138 & 0.053 & 0.138 \\
\hline $\mathrm{NE}_{\mathrm{L}}$-Wheat & 0.369 & 0.008 & 0.372 & 0.112 \\
\hline $\mathrm{NE}_{\mathrm{L}}$-All & $0.586 * *$ & $0.449 * *$ & $0.657^{* *}$ & $0.428 * *$ \\
\hline
\end{tabular}

* Statistically significant at the $p<0.05$ level. ** Statistically significant at the $p<0.01$ level. 
give an acceptable estimation about the continuous high level of crude protein and net energy level (Volkers et al., 2003). Different studies (Lovetta et al., 2004; Lovetta et al., 2005) showed that the NIR method can only be as good as the reference method used, and that Near-infrared (NIR) spectroscopy also has significant potential in the rapid assessment of maize silage, but the predictive accuracy of the model depends on the accuracy of reference samples, the selection of the regression technique used and the sample preparation procedures. Although our study is not a calibration development study, the findings suggest that similar situations may occur in calculations based on the results obtained from a commercial NIR calibration.

Spectral data had significant differences according to sample type in this study as can be seen in Figure 1. This may be attributed that the sample composition and moisture content. Spectral plot has higher peaks region around at $1450 \mathrm{~nm}$ and $1940 \mathrm{~nm}$. These regions are well-known wavelengths related to moisture content in biological samples within scanning interval (Manley, 2014). On the other hand, physical and chemical composition of the sample has

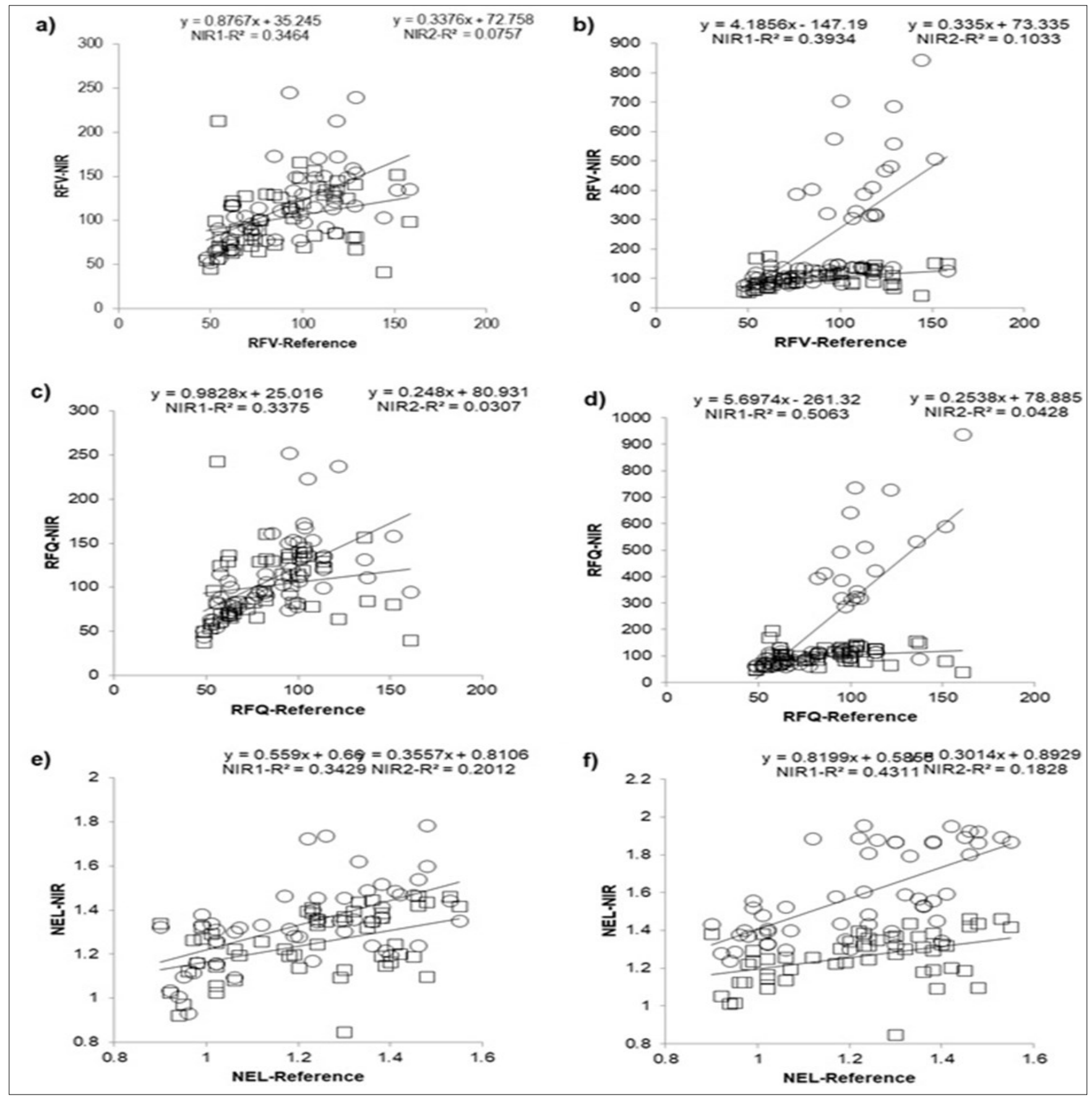

Figure 2. Reference and predicted values for RFV, RFQ and $N_{L}$ in as fed basis $(a, c, e)$ and dry matter basis $(b$, d, f). Circles show NIR1 while squares show NIR2 instrument. 
important effect on the spectral data/plot obtained from the NIR measurement (Pasquini 2003). The same samples can give different spectroscopic information due to differences in their particle size, moisture content as well as other biochemical compounds such as protein, ether extract and starch content. We used roughage samples in the forms of "as fed" and "dry basis" and their biochemical composition show high variability. We must notice that this case must have strong effect on the obtained results from NIR measurements and of course prediction results.

The results of this study have revealed that NIRS method can be used in the quantitative determination of RFV, RFQ and NEL values of roughage. It was determined that used sample type had a significant effect on estimation results, and forage type of roughage was also found to have an effect on the results. The most successful results were obtained from alfalfa samples in the calculation of RFV, RFQ and NEL values from NIR analysis results. In addition to these results, it was observed that the determinations of RFV, RFQ and NEL values may vary according to the used instrument. Even though portability is an important function, it was found out that NIR2 instrument resulted in more deviations compared to NIR1, excluding silage samples. In desktop NIR instrument, the difference between results of silage samples and reference analysis results was determined to be higher than portable NIR instrument. There are several studies for desktop and portable NIR instruments to analyze biological samples. Most of these studies focused on calibration development for both types of instrument. Henn et al. (2016) compared portable versus desktop NIR instrument for analyzing sugar content of different syrup samples. Yu et al. (2020) compare the desktop and portable NIR instrument for discrimination of peanut samples based on fatty acid content. They found comparable results from portable devices with desktop instrument. Our study is not a calibration development research and our findings showed that portable instruments are not sufficient for indirect estimation of RFV, RFQ and NEL values in different roughage samples. Similar results were reported a previous study (Vander Schaaf, 2013) focused on the comparing the prediction performances of desktop and portable (the same instrument in here) NIR instruments for analyzing the components of corn silage and alfalfa hay. This study showed that two instruments gave similar results for dry matter $(r=0.86)$ but no strong correlation for other components such as protein, ash, and fat content. Our results in agreement in this finding and we could associate this result with the measurement capacity of the devices and the type of sample used. The portable device used in this study has a short scanning interval compared to desktop NIR instrument and it has also low scanning intensity. Therefore desktop instrument may give similar results to ref analyses.

\section{Conclusions}

The results indicated that the NIRS method can be used to quantitatively determine the RFV, RFQ and NEL values of roughages. It was determined that the used sample type had a significant effect on the estimation results, and also the type of forage plant from which the roughage was prepared was also effective on the results. The most successful results in the calculation of RFV, RFQ and NEL values based on NIR analysis results were obtained from clover samples. In addition to these findings, it was observed that the determinations of RFV, RFQ and NEL values may change depending on the device used. Although portability is an important function, it has been found that the NIR2 showed more deviation in the results than the NIR1 device, with the exception of silage samples. As to the desktop NIR device, the difference between the results obtained from the silage samples and the reference analysis results was higher than those of the portable NIR device. In the light of the findings of this research, it has been understood that there is a need for calibration development studies to determine RFV, RFQ and NEL values directly with NIR and also special calibrations are needed for roughage sample groups.

\section{Acknowledgments}

This project was funded by Balıkesir University, Scientific Research Projects Commission (BAP: 1502/90, 15-02/091, 15-02/092).

The authors would like to thank Serkan ATEŞ (Department of Animal and Rangeland Sciences, Oregon State University, Corvallis, OR 97333) for his contribution.

\section{Conflict of interest}

Authors have no conflict of interest to declare. 


\section{References}

AOAC (1997). Association of Official Analytical Chemists, 16th ed., Washington, D.C. USA.

Ball, D. M., Hoveland, C. S., \& Lacefield, G. D. (2007). Adapted from Southern Forages, 4 th Ed. International Plant Nutrition Institute. U.S.A.

Gerhardt (2010). Analytical systems documents. Gerhardt $\mathrm{GmbH} \&$ Co.KG Cäsariusstraße 97, Königswinter.

D-53639,

Goldman, A., Genizi, A., Yulzari, A., \& Seligman, N. G. (1987). Improving the reliability of the two stage in vitro assay for ruminant feed digestibility by calibrasyon against intwo data from a wide range of sources. Animal Feed Science and Technology, 18, 233-245.

Hayırlı, A. (2016). Evaluation of roughages. Atatürk Üniversitesi, Rasyonel Hayvancılık ARGE Ata Teknokent, Erzurum.

Henn, R., Schwab, A., \& Huck, C. W. (2016). Evaluation of bench-top versus portable near-infrared spectroscopic method combined with multivariate approaches for the fast and simultaneous quantitative analysis of main sugars in syrup formulations. Food Control, 68, 97-104.

Jaranyama, P., \& Garcia, A. D. (2004). Understanding relative feed value (RFV) and relative forage quality (RFQ). College of Agric and Biological Sci, South Dakota State University, USDA.

Lovetta, D. K., Deavilleb, E. R., Moulda, R., Givensb, D. I., \& Owena, E. (2004). Using near infrared reflectance spectroscopy (NIRS) to predict the biological parameters of maize silage. Animal Feed Science and Technology, 115(1-2), 179-187.

Lovetta, D. K., Deavilleb, E. R., Givensb, D. I., Finlayc, M., \& Owena, E. (2005). Near infrared reflectance spectroscopy (NIRS) to predict biological parameters of maize silage: effects of particle commination, oven drying temperature and the presence of residual moisture. Animal Feed Science and Technology, 120(3-4), 323-332.

Marten, G. C., Shenk, J. S., \& Barton, F. E. (1989). Near infrared reflectance spectroscopy (NIRS): Analysis of forage quality. U.S. Department of agriculture, agriculture handbook No. 643 (revised with supplements), $110 \mathrm{p}$.

Manley, M. (2014). Near-infrared spectroscopy and hyperspectral imaging: non-destructive analysis of biological materials. Chemical Society Reviews, (43), 8200 $-8214$.

NRC (2001). Nutrient requirements of dairy cattle. 7th rev. ed. , Washington DC, USA: National Academy Press.

Parrini, S., Acciaioli, A., Franci, O., Pugliese, C., \& Bozzi, R. (2019). Near infrared spectroscopy technology for prediction of chemical composition of natural fresh pastures, Journal of Applied Animal Research, 47(1), 514520.

Pasquini, C. (2003). Near infrared spectroscopy: fundamentals, practical aspects and analytical applications. Journal of the Brazilian Chemical Society, 14 (2), 198-219.

Pehlevan, F., \& Özdoğan, M. (2015). Comparison between chemical and near Infrared reflectance

spectroscopy methods for determining of nutrient content of some alternative feeds. Journal of Tekirdag Agricultural Faculty, 12(2), 1-10.

Kellems, R. O., \& Church, D. C. (2010). Livestock feeds and feeding (Alp, M., Kocabağlı, N. Ed.) Istanbul, Turkey, Nobel.

Romero, J. J., Castillo, M. S., Burns, J. C., Moriel, P., \& Davidson, S. (2014). Forage quality: concepts and practices, NC State University College of Agriculture and Life Sciences, Published by North Carolina Cooperative Extension.

Rushing, J. B., Saha, U. K., Lemus, R., Sonon, L., \& Baldwin, B. S. (2016). Analysis of some important forage quality attributes of southeastern wildrye (Elymus glabriflorus) using near infrared reflectance spectroscopy. American Journal of Analytical Chemistry (7), 642-662.

Samiei, A., Liang, J. B., Ghorbani, G. R., Hirooka, H., Mahyari, S. A., Sadri, H., \& Tufarelli, V. (2015). Relationship between dietary energy level, silage butyric acid and body condition score with subclinical ketosis incidence in dairy cows. Advances in Animal and Veterinary Sciences, 3(6), 354-361.

SAS (1999). Institute SAS V8 user manual, SAS Cary, NC, USA.

Sheaffer, C. C., Peterson, M. A., McCaslin, M., Volenec, J. J., Cherney, J. H., Johnson, K. D., Woodward, W. T., \& Viands, D. R. (1995). Acid detergent fiber, neutral detergent fiber concentration and relative feed value. North American Alfalfa Improvement Conference, Minneapolis.

Ünal Y. (2005). Near intrared reflektans spektroskopinin hayvan besleme bilim alanında kullanım imkânları. Lalahan Hayvancılık Araştırma Enstitüsü Dergisi, 45(1) 3339.

Van Soest, P. J., Robertson, J. B., \& Lewis, B. A. (1991). Methods for dietary fiber, neutral detergent fiber and non starch polysaccharides in relation to animal nutrition. Journal Dairy Science, (74), 3583-3597.

Van Dyke, N. J., \& Anderson, P. M. (2000). Interpreting a forage analysis. Alabama Cooperative Extension, Circular ANR-890.

Vander Schaaf, D. (2013). Near infrared reflectance spectroscopy comparison of dairy one and agrinir forage analyzer, California Polytechnic State University, San Luis Obispo.

Volkers, K. C., Wachendorf, M., Loges, R., Jovanovic, N., \& Taube, F. (2003). Prediction of the quality of forage maize by near-infrared reflectance spectroscopy. Animal Feed Science and Technology, 109(3), 183-194.

Yang, Z, Nie, G., Pan, L., Zhang, Y., Huang, L., Ma, X., Zhang, $X$. (2017). Development and validation of near infrared spectroscopy for the prediction of for age quality parametersin Lolium multiflorum. Peer Journal 2017;5 :e3867.

Yu, H., Liu, H., Wang, Q., \& Van, Ruth S. (2020). Evaluation of portable and benchtop NIR for classification of high oleic acid peanuts and fatty acid quantitation. LWT, 128, [109398]. 